\title{
BEHAVIORAL PROBLEMS AMONG SCHOOL GOING ADOLESCENTS IN EASTERN DEVELOPMENT REGION OF NEPAL
}

\author{
Kafle $T K^{1^{*}}$, Mashreky $S^{2}$, Kafle $T K^{3}$, Rimal HS ${ }^{4}$, Sapkota $D^{5}$, Pokhrel $A^{6}$
}

\section{Affiliation}

1. Assistant Professor, Department of Community Medicine, Birat Medical College \& Teaching Hospital, Tankisinuwari, Morang, Nepal

2. Lecturer, Department of Community Medicine, Birat Medical College \& Teaching Hospital, Tankisinuwari, Morang, Nepal

3. Associate Professor, Department of Non-Communicable Disease, Bangladesh University of Health Sciences, Dhaka, Bangladesh

4. Professor, Principal \& Head of Department, Department of Padiatrics, Birat Medical College \& Teaching Hospital, Tankisinuwari, Morang, Nepal

5. Research Officer, Milestone Institute of Health Research \& Development, Biratnagar, Nepal

6. Consultant Psychologist, Biratnagar Hospital Biratnagar, Nepal

\section{ARTICLE INFO}

Received : 14 May, 2019

Accepted : 04 August, 2019

Published : 31 August, 2019

(C) Authors retain copyright and grant the journal right of first publication with the work simultaneously licensed under Creative Commons Attribution License CC - BY 4.0 that allows others to share the work with an acknowledgment of the work's authorship and initial publication in this journal.

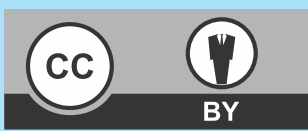

ORA 119

DOI: http://dx.doi.org/10.3126/bjhs.v4i2.25442

\author{
* Corresponding Author \\ Dr. Tara Kumari Kafle \\ Assistant Professor \\ Department of Community Medicine \\ Birat Medical College \& Teaching Hospital \\ E-mail ID: tara.kafle@gmail.com \\ ORCID ID: https://orcid.org/0000-0002-8656-432X
}

\section{Citation}

Kafle TK, Mashreky S, Kafle TK, Rimal HS, Sapkota D, Pokhrel A. Behavioral Problems among School Going Adolescents in Eastern Development Region of Nepal. BJHS 2019;4(2)9: 712-717

\section{ABSTRACT Introduction}

The public health relevance of mental health conditions including behavioural problems in children and adolescents has been a growing concern over the past decades. There are negligible studies found in mental health domains of adolescents in developing countries; studies with regional or national coverage are lacking in Nepal. Therefore, present study has been designed to explore the magnitude and risk factors of behavioral disorders among adolescents.

\section{Objective}

The objective of this study is to examine the prevalence of behavioral disorders and its determinants among school going adolescence in Eastern Development Region of Nepal.

\section{Methodology}

The study adopts analytical cross-sectional design with sample size 1500 involving 11 to 17 year school going adolescents and carried out in Eastern Development Region of Nepal during August to December 2016. Multistage probability sampling technique was used to draw the sample and validated self-report SDQ was used to estimate the behavioral problems. Ethical approval was taken from ERB of Nepal Health Research Council. Written informed consent was taken from each participant before collecting the information. Collected information were entered using Epi Data software and processed to SPSS version 16 for analysis. Both bivariate and multivariate analysis were carried out.

\section{Results}

The prevalence of total (overall) behavioral problem was found among $35.0 \%$ adolescents. While classifying, $13.3 \%$ were suffering from emotional disorder, $11.20 \%$ from conduct problem, $7.2 \%$ from hyperactivity/inattention, $4.9 \%$ from peer relationship problem and $2.1 \%$ from prosocial activities. In multivariate analysis, female adolescents, adolescents of uneducated or less educated parents (less than $10+2)$, residing in mountain ecological belt and adolescents without parents (dead or separated) were found positively associated with behavioral disorders.

\section{Conclusion}

Total behavioral problem was found among 35.0\% adolescents. adolecents of less educated parents, female sex, Mountain ecological belt and those without parents were more vulnerable to behavioral problem. Therefore, parental care seems to be very much essential to reduce the behavioural problems among children.

\section{KEY WORDS}

Behavioural problem, hyper activity, peer problem, mental illness, adolescents 


\section{INTRODUCTION}

Mental disorders comprise a broad range of problems, with different symptoms. However, they are generally characterized by some combination of abnormal thoughts, emotions, behaviour and relationships with others (WHO, 2017). ${ }^{1}$ In medical term, a mental disorder is a syndrome characterized by clinically significant disturbance in an individual's cognition, emotion regulation or behaviourr that reflects a dysfunction in the psychological, biological, or developmental processes underlying mental functioning. Mental disorders are usually associated with significant distress in social, occupational, or other important activities (Eric R., 2013). ${ }^{2}$ Hence, mental disorder refers to a wide range of mental health conditions - disorders that affect individual's mood, thinking and behavior. Mental health disorders among children are described as "serious deprivation from expected cognitive, social, and emotional development" (CDC, 2013). ${ }^{3}$

The public health relevance of mental health conditions in children and adolescents has been a growing concern over the past decades. Evidences have shown that these conditions often continue into adulthood (Merikan gas KR, 2009). ${ }^{4}$ Due to lack of sufficient awareness, mental health is often, hidden and neglected in the family and society, until it reaches in uncontrollable level, especially in developing world. If the problem is not addressed in time the consequences may be serious for children and their family and it affects future productivity and potentiality.

Up to $20 \%$ of children and adolescents suffer from a disabling mental illness globally; and that up to $50 \%$ of all adult mental disorders have their onset in adolescence (Eric R., 2013). ${ }^{2}$ According to the World Health Organization (WHO, 2017), ${ }^{1}$ mental health disorders are one of the leading causes of disability worldwide. Three of ten leading causes of disability in people between ages 15 to 44 years are mental disorders. Many studies have shown that most adulthood mental disorders begin in childhood and adolescence (Murrey C., e, 2002). ${ }^{5}$

The prevalence of child psychiatric disorder in the developed world is $10-20 \%$, but in the developing world, where children and adolescents make up a higher proportion of the population, the prevalence may be higher. Relatively little is known about the extent to which social risk factors identified in the developed world also apply in the developing world (Fleitlich, B and Goodman, R., 2001). ${ }^{6}$ A study conducted in Chandigarh India found 30\% prevalence of behavioural and emotional problems among adolescents with girls exceeding boys in all age groups (Pathak $\mathrm{R}$, et al. 2011). ${ }^{7}$ A cross-sectional study conducted by Rimal HS et al. in Morang district of Nepal between 11-17 years school going adolescents found $18.6 \%$ total mental disorders, $24.5 \%$ emotional problems and $22 \%$ peer relationship problem and the gender difference was also significant statistically (Rimal HS, e., 2014). ${ }^{8}$

Though the public health concern of mental disorders among children and adolescents is growing, there are negligible studies found in this issue in developing countries including Nepal. Moreover, studies which have been conducted in Nepal have limited sample size and very small coverage; no studies with regional or national coverage are found. Therefore, the relevance of present study is felt of great importance. The purpose of the study is to examine the prevalence of mental health disorders and its determinants among school going adolescence in Eastern Development Region of Nepal.

\section{METHODOLOGY}

Analytical cross-sectional study design and quantitative approach of data collection has been adopted in this study. The study was carried out between $1^{\text {st }}$ August to $31^{\text {st }}$ December 2016. In total 20 schools were selected randomly among 7885 schools from Eastern Development Region of Nepal by considering ecological belts. School going adolescents (both girls and boys) ages between 11 to 17 years were studied. The required 1500 sample size was calculated based on the finding of a study conducted in Biratnagar city, Nepal ${ }^{8}$ by using formulae $n=Z^{2} P Q / d^{2}$ and design effect 2 .

The multistage (three stage) cluster sampling technique was adopted to draw the sample from population. In the first stage, five districts were selected by using Simple Random Sampling (SRS) technique considering ecological belts (1 from Mountain, 2 from Hill and two from Terai). In second stage, four schools from each district were selected randomly, and in third stage participants were selected by using simple random sampling technique. Equal sample size was taken from each district i.e.300. Standard and valid Strengths and Difficulties Questionnaire (SDQ) was used to collect the behavioural problems related information and socio-demographic information were also collected by using the standard pre-designed questionnaire. The individual data were entered into Microsoft computer using EpiData version 3.1 software and processed further to the SPSS version 16 for analysis. Both bivariate and multivariate analysis were carried out. Chi-square test is used to test association between variables as a part of bivariate analysis and logistic regression analysis is used to identify the risk factors in multivariate analysis. Statistical test were done at 95\% confidence interval. Written informed consent was taken from each participants and concerned school authority before data collection. The ethical approval was taken from Ethical Review Board of Nepal Health Research Council, Kathmandu.

\section{RESULTS}

Table 1 reveals the socio-demographic information of the study subjects. Among 1500 school going adoloscents, 56\% respondents were female and the mean age was 14.78 years with SD 1.5.

Similarly, three in every five (59.1\%) respondents were 14 
years and older and higher proportion of the respondents were belonged to Janajati/Adibasi ethnic group (39.9\%) followed by hill Brahmin/Chhetri (30.5\%)

Sixty three percent respondents were residing in nuclear family structure and about $57 \%$ respondents had low property indenx in family. As the equal sample size was taken from each district, $40 \%$ respondents were from each

\begin{tabular}{|c|c|c|c|}
\hline Variables & & $\begin{array}{l}\text { Frequency } \\
(n=1500)\end{array}$ & $\begin{array}{c}\text { Percentage } \\
\text { (\%) }\end{array}$ \\
\hline Age & $\begin{array}{l}11-14 \text { yrs } \\
>14 y r s \\
\text { Mean } \pm S D\end{array}$ & $\begin{array}{c}614 \\
886 \\
14.78 \pm 1.53\end{array}$ & $\begin{array}{c}40.9 \\
59.1 \\
-\end{array}$ \\
\hline Sex & $\begin{array}{l}\text { Male } \\
\text { Female }\end{array}$ & $\begin{array}{l}663 \\
837\end{array}$ & $\begin{array}{l}44.2 \\
55.8\end{array}$ \\
\hline Ethnicity & $\begin{array}{l}\text { Hill Upper Caste } \\
\text { Terai Upper caste } \\
\text { Janjati/Adibasi } \\
\text { Dalits } \\
\text { Others }\end{array}$ & $\begin{array}{c}457 \\
305 \\
599 \\
114 \\
25\end{array}$ & $\begin{array}{c}30.5 \\
20.3 \\
39.9 \\
7.6 \\
1.7\end{array}$ \\
\hline Type of Family & $\begin{array}{l}\text { Nuclear } \\
\text { Joint }\end{array}$ & $\begin{array}{l}951 \\
549\end{array}$ & $\begin{array}{l}63.4 \\
36.6\end{array}$ \\
\hline Property index & $\begin{array}{l}\text { Low } \\
\text { Middle } \\
\text { High } \\
\text { Terai }\end{array}$ & $\begin{array}{l}851 \\
284 \\
364 \\
600\end{array}$ & $\begin{array}{c}56.70 \\
18.90 \\
24.30 \\
40.0\end{array}$ \\
\hline Ecological Belt & $\begin{array}{l}\text { Hill } \\
\text { Mountain }\end{array}$ & $\begin{array}{l}600 \\
300\end{array}$ & $\begin{array}{l}40.0 \\
20.0\end{array}$ \\
\hline
\end{tabular}

The educational status of respondents' parents was found poor. However, fathers had better educational status as compared to their mothers. More than $26 \%$ mothers had no education, and it was around $10 \%$ for fathers.

About one third $(32.5 \%)$ respondents reported that their fathers had some secondary level education in contrast to $26.3 \%$ mothers. Only about $20 \%$ fathers and $9 \%$ percent had higher education (10+2 and above) (Table 2 ).

Table 2: Distribution of respondents by their Parents' Education

\begin{tabular}{|ccc}
\multicolumn{1}{|c|}{ Variables } & $\begin{array}{c}\text { Frequency } \\
(\mathbf{n}=\mathbf{1 5 0 0 )}\end{array}$ & Percentage (\%) \\
\hline Father's Education & 161 & 10.7 \\
No education & 292 & 19.5 \\
Primary & 487 & 32.5 \\
Secondary & 237 & 15.8 \\
SLC Pass & 191 & 12.7 \\
Higher Secondary & 100 & 6.7 \\
Bachelors Plus & 32 & 2.1 \\
Not responded & & \\
Mother's Education & 402 & 26.8 \\
No Education & 377 & 25.1 \\
Primary & 395 & 26.3 \\
Secondary & 162 & 10.8 \\
SLC Pass & 101 & 6.7 \\
Higher Sec & 36 & 2.4 \\
Bachelors Plus & 26 & 1.7 \\
Not responded & &
\end{tabular}

Some questions related to environment for adolescents' psychological support had been asked. About 70 percent adolescents were currently living with both parents and 93.3\% respondents were belonging to both parents (not separated/died). Most of them (88.30\%) reported that they were receiving good parental care. Majority (59.9\%) of the school going adolescents were getting positive environment in the school and only 1 in every 8 adolescent was involving in regular outdoor activities/games and sports (Table 3).

Table 3: Supportive Environment at Home and School for the Adolescents

$\begin{array}{llcc}\text { Variables } & \text { Frequency } & \begin{array}{c}\text { Percentage (\%) } \\ (\mathbf{n}=\mathbf{1 5 0 0})\end{array} & \\ \text { Parent's Status } & \text { Belong Both parents } & 1,400 & 93.30 \\ & \text { Only Father } & 25 & 1.70 \\ & \text { Only Mother } & 51 & 3.40 \\ & \text { Step Mother/Father } & 23 & 1.50 \\ \text { Parent's Care } & \text { Good } & 1,324 & 88.30 \\ & \text { Normal } & 161 & 10.70 \\ \text { School Environment } & \text { Bad } & 15 & 1.00 \\ & \text { Positive } & 924 & 61.60 \\ & \text { Normal } & 553 & 36.90 \\ \text { Outdoor Activities } & \text { Negative } & 23 & 1.50 \\ & \text { Always } & 178 & 11.90 \\ & \text { Mostly } & 279 & 18.60 \\ & \text { Sometimes } & 898 & 59.90 \\ & \text { Rarely } & 145 & 9.70\end{array}$

Among 1500 adolescents, 35\% had abnormal behavioural difficulties and another $30.7 \%$ were in boarder line indicating vulnerability of abnormal difficulties in future (Table 4). The mental health difficulties (behavioural problem) as assessed by SDQ have been divided into five major areas: emotion, conduct, hyperactivity, peer relationship and pro-social activity. While segregating individual difficulties, $13.3 \%$ had emotional difficulties, $11.20 \%$ had difficulties related to their conduct, $7.2 \%$ had hyperactivity, $4.9 \%$ had difficulties in peer relationship and only $2.1 \%$ had pro-social activities and additional significant proportion of adolescents also had boarder line difficulties in various behavioural aspects (Table 4).

Table 4: Distribution of respondents by mental health difficulties

$\begin{array}{llcc}\text { Characteristics } & & \text { Frequency } & \text { Percentage } \\ \text { Emotions } & \text { Normal } & 1,153 & 76.90 \\ & \text { Borderline } & 147 & 9.80 \\ & \text { Abnormal } & 200 & 13.30 \\ \text { Conduct } & \text { Normal } & 1,159 & 77.30 \\ & \text { Borderline } & 173 & 11.50 \\ & \text { Abnormal } & 168 & 11.20 \\ \text { Hyperactivity } & \text { Normal } & 1,226 & 81.70 \\ & \text { Borderline } & 166 & 11.10 \\ \text { Peer Relationship } & \text { Abnormal } & 108 & 7.20 \\ & \text { Normal } & 1,188 & 79.20 \\ & \text { Borderline } & 238 & 15.90 \\ \text { Pro-social Activities } & \text { Abnormal } & 74 & 4.90 \\ & \text { Normal } & 1,403 & 93.50 \\ & \text { Borderline } & 66 & 4.40 \\ \text { Total difficulties (Overall) } & \text { Abnormal } & 31 & 2.10 \\ & \text { Normal } & 515 & 34.30 \\ & \text { Boarder line } & 460 & 30.70 \\ & \text { Abnormal } & 525 & 35.00\end{array}$


The significance has been tested using Pearson's chi-square test of association. The $95 \%$ confidence interval is considered. Table 5 reveals the cross-analysis of total (overall) behavioural difficulties with various sociodemographic factors. The age, sex, ethnicity, type of family, ecological belt of residence, currently living with, parental status, parents' care, school environment (as rated by respondent), involvement in games and sports (outdoor activity), and parents education were the variables considered.

\begin{tabular}{|c|c|c|c|c|c|}
\hline Socio-Demograp & hic Variables & $\begin{array}{l}\text { Normal } \\
\text { N (\%) }\end{array}$ & $\begin{array}{l}\text { Total di sorders } \\
\text { Boarder Line } \\
\mathrm{N}(\%)\end{array}$ & $\begin{array}{c}\text { Abnormal } \\
\mathrm{N}(\%)\end{array}$ & $\begin{array}{l}\text { Chi-square } \\
\text { and p value }\end{array}$ \\
\hline Age & $11-14$ yrs & $231(37.6)$ & $184(30.0)$ & $199(32.4)$ & $x^{2}=5.43$ \\
\hline & $>14 \mathrm{yrs}$ & $284(32.1)$ & $276(31.2)$ & $326(36.8)$ & $P=.066$ \\
\hline Sex & Male & 264(39.8) & $212(32.0)$ & $187(28.2)$ & $x^{2}=26.75$ \\
\hline & Female & $251(30.0)$ & $248(29.6)$ & $338(40.4)$ & $P<.001$ \\
\hline Ethnicity & Hill upper caste & $157(34.4)$ & $153(33.5)$ & $147(32.2)$ & \\
\hline & Terai upper caste & $122(40.0)$ & $81(26.6)$ & $102(33.4)$ & $x^{2}=10.75$ \\
\hline & Janjati/adhibasi & $188(31.4)$ & $185(30.9)$ & $226(37.7)$ & $P=0.216$ \\
\hline & Dalits & $38(33.3)$ & $33(28.9)$ & $43(37.7)$ & \\
\hline & Others & $10(40.0)$ & $8(32.0)$ & $7(28.0)$ & \\
\hline Type of family & Nuclear & 334 (35.1) & $273(28.7)$ & $344(36.2)$ & $x^{2}=4.75$ \\
\hline & Joint & $181(33.0)$ & $187(34.1)$ & $181(33.0)$ & $\mathrm{p}=0.093$ \\
\hline Parents' status & Both parents & $491(35.1)$ & $435(31.1)$ & $474(33.9)$ & \\
\hline & Only father & $7(28.0)$ & $6(24.0)$ & $12(48.0)$ & $x^{2}=18.05$ \\
\hline & Only mother & $14(27.5)$ & $15(29.4)$ & $22(43.1)$ & $p=0.006$ \\
\hline & Step parents/none & $3(12.5)$ & $4(16.7)$ & $17(70.8)$ & \\
\hline Parents' care & Good & $458(34.6)$ & $413(31.2)$ & $453(34.2)$ & \\
\hline & Normal & $54(33.8)$ & $45(28.0)$ & $62(38.5)$ & \\
\hline & Bad & $3(20.0)$ & $2(13.3)$ & 10(66.7) & $p=0.09$ \\
\hline School Environment & Positive & $322(34.8)$ & $282(30.5)$ & $320(34.6)$ & $x^{2}=3.22$ \\
\hline & Normal & $187(33.8)$ & 173(31.3) & 193(34.9) & $\mathrm{p}=0.522$ \\
\hline & Negative & $6(26.1)$ & $5(21.7)$ & $12(52.2)$ & \\
\hline & Terai & $221(36.8)$ & $185(30.8)$ & 194(32.3) & \\
\hline Ecological belt & Hill & $224(37.3)$ & $179(29.8)$ & $197(32.8)$ & 3.59 \\
\hline & Mountain & $70(23.3)$ & $96(32.0)$ & $134(44.7)$ & $p<0.001$ \\
\hline & First & $178(34.7)$ & $142(27.7)$ & 193(37.6) & \\
\hline & Second & $162(33.1)$ & $143(29.2)$ & 184(37.6) & $x^{2}=15.37$ \\
\hline Property Index & Third & 95(31.9) & $106(35.6)$ & $97(32.6)$ & $p=0.018$ \\
\hline & Forth & $80(40.0 .0)$ & $69(34.5)$ & $51(25.5)$ & \\
\hline
\end{tabular}

While analysing overall disorders, among various sociodemographic factors, age, sex, parent's status, parents' care, ecological belt, and property index of the family were significantly associated with the behavioural disorders of the adolescents (Table 5).

Table 5a: Distribution of respondents with total mental disorders by Parent's Characteristics

\begin{tabular}{|c|c|c|c|c|c|}
\hline & Variables & $\begin{array}{l}\text { Normal } \\
\text { N (\%) }\end{array}$ & $\begin{array}{l}\text { Total Difficulti } \\
\text { Boarder line } \\
\text { N (\%) }\end{array}$ & $\begin{array}{l}\text { Abnormal N } \\
(\%)\end{array}$ & $\begin{array}{l}\text { Chi-Square } \\
\text { and } P \text { value }\end{array}$ \\
\hline \multirow{6}{*}{$\begin{array}{l}\text { Father's } \\
\text { Education }\end{array}$} & Not Responded & $9(28.1)$ & $11(34.4)$ & $12(37.5)$ & \multirow{7}{*}{$\begin{array}{l}\chi^{2}=16.15 \\
p=0.184\end{array}$} \\
\hline & No education & $48(29.8)$ & $47(29.2)$ & $66(41.0)$ & \\
\hline & $\begin{array}{l}\text { Primary } \\
\text { Secondary }\end{array}$ & $\begin{array}{c}97(33.2) \\
160(32.9)\end{array}$ & $\begin{array}{c}81(27.7) \\
153(31.4)\end{array}$ & $\begin{array}{l}114(39.0) \\
174(35.7)\end{array}$ & \\
\hline & SLC Pass & $86(36.3)$ & $77(32.5)$ & $74(31.2)$ & \\
\hline & Higher Secondary & $71(37.2)$ & $57(29.8)$ & $63(33.0)$ & \\
\hline & Bachelors Plus & $44(44.0)$ & $34(34.0)$ & $22(22.0)$ & \\
\hline Mother's & Not Responded & $7(26.9)$ & $9(34.6)$ & $10(38.5)$ & \\
\hline \multirow[t]{6}{*}{ Education } & No Education & $129(32.1)$ & $124(30.8)$ & $149(37.1)$ & \multirow{6}{*}{$\begin{array}{l}\chi^{2}=6.61 \\
P=0.882\end{array}$} \\
\hline & Primary & $132(35.0)$ & $109(28.9)$ & $136(36.1)$ & \\
\hline & Secondary & $137(34.7)$ & $123(31.1)$ & $135(34.2)$ & \\
\hline & SLC Pass & $61(37.7)$ & $47(29.0)$ & $54(33.3)$ & \\
\hline & Higher Sec & $35(34.7)$ & $33(32.7)$ & $33(32.7)$ & \\
\hline & Bachelors Plus & $13(36.1)$ & $15(41.7)$ & $8(22.2)$ & \\
\hline Total & & $515(34.3)$ & $460(30.7)$ & $525(35.0)$ & \\
\hline
\end{tabular}

Multivariate Analysis has been done to know the risk factors for behavioural disorders among the children. Among 15 variables: age, sex, family type, father's and mother's education, school environment, ecological belt, parent's status, parent's care, living with were played in logistic regression, only sex, ecological belt, parents' education (father) and parent's belongingness status were found significantly associated with behavioural disorders. Female adolescents, adolescents with less educated parents, who were residing in Mountain belt and who were living with step mother/father or living without parents were more vulnerable to behavioural disorders than their counterparts.

\begin{tabular}{|c|c|c|c|c|}
\hline \multirow{2}{*}{ Determinants } & \multirow{2}{*}{$\mathbf{N}$} & \multirow{2}{*}{ OR } & \multicolumn{2}{|c|}{ Binary Logistic Regression } \\
\hline & & & AOR & Cl \\
\hline \multicolumn{5}{|l|}{ Sex } \\
\hline Male & 663 & 1.00 & 1.00 & Ref\# \\
\hline Female & 837 & 1.75 & 1.69 & $1.35-2.11^{* * *}$ \\
\hline \multicolumn{5}{|l|}{ Ecological Belt } \\
\hline Terai & 600 & 1.00 & 1.00 & Ref\# \\
\hline Hill & 600 & 0.95 & 1.10 & $0.86-1.42$ \\
\hline Mountain & 300 & 1.62 & 1.79 & $1.34-2.41^{* * *}$ \\
\hline \multicolumn{5}{|l|}{ Parents Status } \\
\hline Both Parents & 1400 & 1.00 & 1.00 & Ref\# \\
\hline Only Father & 25 & 2.08 & 1.80 & $0.79-4.11$ \\
\hline Only Mother & 51 & 1.34 & 1.39 & $0.75-2.58$ \\
\hline Step Parents/None & 24 & 3.37 & 4.62 & $1.88-11.38^{* * *}$ \\
\hline \multicolumn{5}{|l|}{ Father's Education } \\
\hline No Education & 158 & 1.77 & 2.53 & $1.40-4.57 * *$ \\
\hline Primary & 287 & 1.70 & 2.07 & $1.20-3.57^{* *}$ \\
\hline Secondary & 485 & 1.48 & 1.83 & 1.09-3.09* \\
\hline SLC & 235 & 1.17 & 1.54 & $0.88-2.70$ \\
\hline Higher Secondary & 190 & 1.51 & 1.65 & $0.93-2.92$ \\
\hline Bachelor Plus & 100 & 1.00 & 1.00 & Ref\# \\
\hline
\end{tabular}

*significant at $95 \% \mathrm{Cl}, * *$ significant at $99 \% \mathrm{Cl}, * * *$ significant at $99.9 \% \mathrm{Cl}$

The females had 1.69 times higher odds to get behavioural abnormality $(\mathrm{Cl}: 1.41-2.16,95 \%, \mathrm{p}<0.001)$ than males. Similarly, adolescents from Mountain Ecological Belt had 1.79 times higher odds than those from Terai (AOR 1.79, $95 \%, p<0.001)$. The adolescents from Hill ecological belt had comparatively lower risk of getting suffered from behavioural disorders than other ecological belts.

The parent's status had played a vital role in the bahavioural status of their children. Adolescents without parents or with step parents were found at higher risk of behavioural disorders; the odds of adolescents without parents had 4.62 times higher ( $\mathrm{Cl}: 1.88-11.38,95 \%, \mathrm{p}<0.001)$ to get disorders than those living with both parents. Fathers' education also negatively associated with behavioural problems. Adolescents with not educated fathers were 2.53 (Cl: 1.20 $3.57,95 \%, p<0.01)$ times more likely and with father's primary education were 2.07 ( $\mathrm{Cl}: 1.20-3.57,95 \%, \mathrm{p}<0.01)$ times more likely to have behavioural problem as compared to adolescents with father's education bachelors and above (Table 6). 


\section{DISCUSSION}

The public health relevance of mental health conditions in children and adolescents has been a growing concern over the past decades. Evidences have shown that these conditions often continue into adulthood and up to $50 \%$ of all adult behavioural disorders have their onset in adolescence (Eric R, 2013 and Merikangas, 2009) 2,4. Though the problem is emerging, sufficient studies have not been conducted yet. Present study has used self rated Strength and Difficulties Questionnaire (SDQ) with impact supplement (two sided version) to rate the mental health disorders among 11 to 17 years old school going adolescents. In this study about 35\% adolescent found with anyone mental disorders (behavioral abnormalities). While analyzing different domains, $13.3 \%$ were suffering from emotional disorder, $11.20 \%$ from conduct related disorder, $7.2 \%$ from hyperactivity/inattention, $4.9 \%$ from difficulties in peer relationship and $2.1 \%$ had pro-social activities. Additional significant numbers of adolescents were in boarder line in various mental health domains. A research conducted by Bhola P et al $(2016)^{9}$ among 1087 pre-university students in Bangalore, India using the self-reported Strengths and Difficulties Questionnaire (SDQ) found abnormal total difficulties among $10.1 \%$ adolescents, with $9 \%$ at risk for emotional symptoms, $13 \%$ for conduct problems, $12.6 \%$ for hyperactivity/inattention and $9.4 \%$ for peer problems. This finding is similar in many aspects with present finding; however, present finding found higher prevalence of mental difficulties among adolescents, this could be due to increasing junk food pattern and growing individualism. Another study conducted by Antilola A, et al found the prevalence of self-reported mental health problems among $10.5 \%$ (ranging, 5.8-15) adolescents with conduct and emotional problems being the most prevalent. A cross-sectional study conducted by Rimal HS in Biratnagar, Nepal $^{8}$ also found abnormal total difficulties among $18.6 \%$ adolescents with $24 \%$ emotional difficulties. This finding keeps much similarity with present finding. Syed EU et $\mathrm{al}^{10}$ conducted a cross sectional study on Prevalence of emotional and behavioural problems among primary school children in Karachi, Pakistan--multi informant survey among 1488 parents and teachers using Strengths and Difficulties Questionnaire (SDQ). Where the parents rated $34.4 \%$ of children as falling under the "abnormal" category, slightly higher estimates $35.8 \%$ were reported by the teachers. The findings suggest a striking difference between the informants' ratings as well as gender wise difference in prevalence of common child mental health problems. Another cross-sectional study conducted by Hackett R et al $(1999)^{11}$ reported that $18 \%$ of pupils found abnormal on the SDQ as rated by teachers. The study by Reinholdt-Dunne MLet $\mathrm{al}^{12}$ found that $10.8 \%$ of children had concerns regarding emotional difficulties and that significantly more girls than boys reported this concern. This finding keeps some similarity with present finding as females were suffering more than males in total behavioral problems and also property index of family is associated with mental health problems of children.

Age, sex, parent's status, parents' care, ecological belt, and property index of the family were significantly associated with total mental abnormality in bi-variate analysis. Multivariate analysis was also done to know the risk factors for total mental health disorders among the adolescents. Among 15 variables adjusted only sex, ecological belt, parent's status and father's education were found significantly associated with total disorders. Adolescents from female sex, who were residing in Mountain ecological belt, who were with step mother/father (without parents) and without educated fathers were much more vulnerable of suffering from the behavioural disorders than their counterparts. The parent's living status has played a vital role in the mental health status of children. Adolescents with without parents were found in higher risk of getting suffered; the odds of adolescents without parents had 3.37 times higher and only father had 2.08 times higher than those living with both parents. The finding of Rimal HS et al ${ }^{8}$ compatible with present findings as he found that girls were significantly more likely to have emotional problems than boys ( $p$ value $<0.05$ ). Gender difference was also significant statistically as girls had higher abnormal total SDQ score than boys ( $p$ value $<0.05$ ). Another study conducted by Reinholdt-Dunne ML et al. ${ }^{12}$ found the variables as living with single parents or other nonparent care givers, having a chronic disabling physical condition, lower maternal education, and coming from a family in the lower FAS-score category were all independently associated with higher odds of mental health problems, after controlling for all potential socio-demographic confounders.

\section{LIMITATION OF THE STUDY}

Behavioural difficulties of the adolescents has been attempted to estimate only by using SDQ and it may not cover all dimensions of mental health. Study covers the information of 11-17 years adolescents who were attending to the school. The characteristics of out school adolescents might not be represented by the study.

\section{CONCLUSION}

The prevalence of total (overall) behavioural abnormalities was found much higher among school going adolescents in Eastern Nepal (35\%). Proportion of emotional problems were found most common domain, conduct disorder and hyperactivity/ inattention also found significant in volume. Female sex, parent's non-belongingness, Mountain ecological belt and parent's education (father) were found significantly associated with behavioural problems. 


\section{RECOMMENDATION}

Policy should be formulated to create the positive environment in the school as well as community to protect the mental health and psychology of the children. Training in responsible parenting should be explored to maintain good environment at home and training also be provided to the teachers to encourage children towards positivism and to handle children with mental difficulties. A nationwide research is essential to dig out the real problem of adolescents in Nepal. There is also a scope for operational research on mental health particularly behavioural issues to establish causal relationship.

\section{REFERENCES}

1. World Health Organization. Health Topics: Mental Disorders. [Internet] available: http://www.who.int/topics/mental_disorders /en/ [21. March 2017].

2. Eric R. Rethinking Mental Health; A new Definition of Mental Disorder. Internet download (Available): https://www.psychologytoday.com /blog/rethinking-psychology/201307/the-new-definition-mentaldisorder

3. Centre for Disease Control and Prevention (CDC), Mental Health Surveillance Among Children-United States, 2005-2011. Supplements, May 17, 2013 /62(02);1-35. Internet available: www.cdc.gov

4. Merikangas KR. Epidemiology of mental disorders in children and adolescents; Dialogue in Clinical Neurosci.2009 Mar;11(1): 7-20.

5. Murray C., Lopaz A. World Health Report 2002: Reducing Risk, Promoting Healthy Life. Geneva, Switzerland: World Health Organization.

6. Fleitlich B. and Goodman R. Social factors associated with child mental health problems in Brazil: cross sectional survey.2001; BMJ Vol.323:599 doi: https://doi.org/10.1136/bmj.323.7313.599

7. Pathak R, Sharma C, et.al. Behavioural and Emotional Problems in School Going Adolescents. Australas Med J. 2011:4(1): 15-21.

8. Rimal, HS. Pokharel, A. Shah, A. Giri A. et al. Burden of Developmental and Behavioural Problems among Children Descriptive Hospital Based Study. Journal of Nobel Medical College, Vol. 3 No.1 Issue 5 (2014); 45-49.

9. Bhola, P., Sathyanarayanan, V., Rekha, D., Daniel, S. and Thomas, T. Assessment of self-reported emotional and behavioral difficulties among pre-university college students in Bangalore, India. Indian Journal of Community Medicine 41(2):146-150 • February 2016;

10. Syed EU, et. al. Prevalence of emotional and behavioural problems among primary school children in Karachi, Pakistan--multi informant survey. 2017; PubMed, NCBI. [online] Ncbi.nlm.nih.gov. Available at: https://www.ncbi.nlm.nih.gov/pubmed/19390811 [Accessed 16 Mar. 2017].

11. Hackett R, Hackett L, Bhakta P, Gowers S. The pre-valence and associations of psychiatric disorder in children in Kerala, South India. 1999; J Child Psychol Psychiatry 40(5):801-807.

12. Reinholdt-Dunne ML, Mogg K, Benson V, Bradley BP. Anxiety and selective attention to angry faces: An antisaccade study. 2012; Journal of Cognitive Psychology 24(1):54-65 - February 2012 with 82 Reads. DOI: 10.1080/20445911.2011.560111 